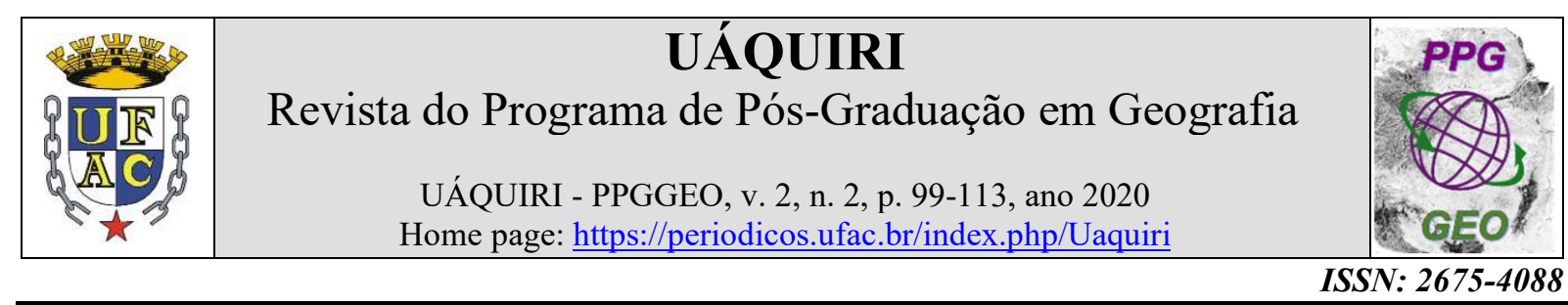

\title{
PROPOSTA METODOLÓGICA PARA COLETA E MONITORAMENTO DE SEDIMENTOS DE FUNDO EM CORPOS HIDRICOS LÊNTICOS
}

\author{
Aniely Souza de Araújo ${ }^{1}$, Bel. Anderson Lisboa do Nascimento ${ }^{1}$, Gabriel Aguiar da Silva ${ }^{1}$, \\ Dr. Waldemir Lima dos Santos ${ }^{2}$, Dr. José Genivaldo do Vale Moreira, \\ Dr. Rodrigo Otavio Peréa Serrano ${ }^{2,3}$. \\ ORCID: https://orcid.org/0000-0002-9973-4201; https://orcid.org/0000-0003-0546-2135; \\ https://orcid.org/0000-0003-2540-9518; https://orcid.org/0000-0002-5306-5612; \\ https://orcid.org/0000-0002-5306-5612; https://orcid.org/0000-0002-7786-8305

\begin{abstract}
${ }^{1}$ Curso de Geografia (bacharelado) da UFAC, Rio Branco, Acre, Brasil. ${ }^{2}$ Professor do Programa do Pósgraduação em Geografia da Universidade Federal do Acre (UFAC), Rio Branco, Acre, Brasil; ${ }^{3}$ Professor do Programa de Pós-graduação em Ciência, Inovação e Tecnologia para a Amazônia da UFAC, Rio Branco, Acre, Brasil;

*anniely.wanda.rosa@gmail.com
\end{abstract}

Recebido em: 13/05/2020. Aceito em: 23/09/2020. Publicado em: 20/12/2020 DOI: https://doi.org/10.47418/uaquiri.vol2.n2.2020.3645

\begin{abstract}
RESUMO
O transporte e sedimentação de material particulado em suspensão nos corpos hídricos dependem da origem do material (rocha, solo, matéria orgânica etc.), da cobertura vegetal, declividade do escoamento e do regime de chuvas. Além disso, a dinâmica dessa partícula sofre influência da dinâmica do fluido (água), que as mantém em suspensão, transportando-as na direção do fluxo de escoamento. Para iniciar o entendimento dessa dinâmica, o presente trabalho apresenta um modelo de aparato, voltado à coleta de material decantado em ambiente lêntico (açude). Foi construído com material reciclado, tendo como base principal, um balde de $18 \mathrm{~L}$ de gordura vegetal. Dessa forma, as medidas dos baldes foram ajustas para altura de $13 \mathrm{~cm}$ e a estrutura lateral foi reforçada. As coletas foram realizados em 2 açudes da Universidade Federal do Acre (UFAC) e o tempo de amostragem de material decantado foi de $48 \mathrm{~h}, 120 \mathrm{~h}$ e 196h, obtendo-se os seguintes resultados: (i) Inicialmente o aparato apresentou bons resultados, mostrando uma tendência no acúmulo de sedimentos ao longo do tempo; (ii) recomenda-se novas repetições ao longo do ano hidrológico para identificação da influência da precipitação na decantação dos sedimentos; (iii) Equipamento simples e pouco oneroso, pode gerar informações importantes para determinar o comportamento dos sedimentos em ambiente fluvial.
\end{abstract}

Palavras-chave: Decantação; Sedimentologia; Transporte de sedimento.

\section{METHODOLOGY FOR SEDIMENT MONITORING IN LENTIC WATER BODIES}

\begin{abstract}
The transport and sedimentation of particulate material in suspension in waterbodies depends on the origin of the material (rock, soil, organic matter, etc.), the vegetation cover, the declivity of the flow and the rainfall regime. Besides that, the dynamics of this particle is influenced by the dynamics of the fluid
\end{abstract}


(water), which keeps them in suspension, transporting them in the direction of the flow. To begin the understanding of this dynamic, the present work presents an apparatus model, aimed at the collection of decanted material in a lentic environment (stream). It was built with recycled material, having as main base, an 18L bucket of vegetable fat. This way, the buckets measurements were adjusted to a height of $13 \mathrm{~cm}$ and the lateral structure was reinforced. The collections were made in 2 streams of the Federal University of Acre (UFAC) and the sampling time of decanted material was $48 \mathrm{~h}, 120 \mathrm{~h}$ and $196 \mathrm{~h}$, obtaining the following results: (I) Initially, the apparatus presented good results, showing a trend in sediment accumulation over time; (II) New repetitions along the hydrological year are recommended to identify the influence of precipitation on sediment decantation; (III) Simple and inexpensive equipment can generate important information to determine sediment behavior in a river environment.

Keywords: Decantation; Sedimentology; Sediment transport.

\title{
METODOLOGÍA PARA EL MONITOREO DE SEDIMENTOS EN CUERPOS HIDRO LÉNICOS
}

\begin{abstract}
RESUMEN
El transporte y sedimentación del material reducido a partículas en suspensión en los cuerpos hídricos dependen del origen del material (roca, suelo, materia orgánica, etc.), de la cubierta vegetal, de la cuesta del escurrimiento y del régimen de lluvias. Además, la dinámica de esta partícula sufre influencia por la dinámica del fluido (agua), que las mantiene en suspensión, transportándolas en la dirección del flujo del escurrimiento. Para empezar la comprensión de esta dinámica, el presente trabajo presenta un modelo de aparato, vuelto a la recolección de material decantado en un ambiente lentico (embalse). Fue construido con material reciclado, teniendo como base principal un cubo de $18 \mathrm{~L}$ de grasa vegetal. Así, las medidas de los cubos fueron ajustadas a una altura de $13 \mathrm{~cm}$ y se reforzó la estructura lateral. Las recolecciones se realizaron en 2 embalses de la Universidad Federal de Acre (UFAC) y el tiempo de muestreo del material decantado fue de $48 \mathrm{~h}, 120 \mathrm{~h}$ y $196 \mathrm{~h}$, se obteniendo los siguientes resultados: (i) A principio el aparato presentó buenos resultados, mostrando una tendencia en la acumulación de sedimentos a lo largo del tiempo; (ii) se recomienda nuevas repeticiones a lo largo del año hidrológico para identificación de la influencia de la precipitación en la decantación de sedimentos; (iii) Equipamiento simple y poco oneroso, puede generar informaciones importantes para determinar el comportamiento de los sedimentos en un ambiente fluvial.
\end{abstract}

Palabras llave: Decantación; Sedimentología; Transporte de sedimento.

\section{INTRODUÇÃO}

A deposição de sedimentos em reservatório é um processo complexo que depende de vários fatores, e as interações desses fatores fazem com que os processos de deposição em cada reservatório sejam únicos. Neste contexto, Loureiro (2008, p.29) explicita que "embora o fluxo e deposito de sedimentos em rios sejam de grande importância, uma maior atenção tem sido dada a deposição em lagos e reservatórios".

A compreensão dos processos que envolvem o transporte e deposição de sedimento em reservatórios parte da identificação, descrição e quantificação dos principais processos que causam a movimentação da rocha mãe e os processos erosivos.

Os sedimentos semifluidos podem ser carreados e depositados para o leito de um lago ou reservatório. Além disso, costuma ocorrer à deposição de matéria orgânica em decomposição 
originada da própria bacia ou da água do lago, que acaba por se misturar aos sedimentos outrora carreados (SILVA; SCHULZ, 2004).

A construção de uma barragem para a formação de açude em curso d'água altera as características hidrológicas do leito original da rede de drenagem, decorrente do aumento da área alagada e diminuição da velocidade média do fluxo de escoamento. Essa redução de velocidade reduz a capacidade de transporte dos sedimentos, proporcionando sua precipitação junto ao talvegue do lago (PAIVA; PAIVA, 2003).

A retirada da vegetação, o manejo inadequado do solo e a ocupação urbana acelerada nas áreas do entorno de rios ou açudes influenciam, diretamente, os regimes hidrológicos, hidráulicos e sedimentológicos, além da qualidade das águas superficiais (BELLINASO; PAIVA, 2007).

De modo geral, os lagos e açudes são reservatórios extremamente importantes em algumas regiões, sendo usados para complementar à captação de água, para suprir as necessidades da população, atividades agropecuárias e dessedentação de animais. Os reservatórios de água estão sujeitos a alguns impactos resultante dos processos erosivos que ocorrem nos rios, notadamente quanto aos picos de cheia e vazante, sendo que na cheia há a saturação das margens e, na vazante, apresenta erosão por corrosão, culminando com a queda de blocos por desmonte hidráulico. No entanto, devido à baixa velocidade das águas, diminuise a capacidade de transporte de sedimentos.

Vários mecanismos atuam na estrutura vertical e horizontal dos lagos, influenciando diretamente em sua característica. Entre os principais mecanismos encontra-se: os mecanismos externos como vento; transferência de calor e descargas na superfície; e os mecanismos internos como a formação de ondas internas; retirada seletiva e misturas vertical. Tanto os mecanismos internos e externos sofrem a influência de fatores climatológicos e hidrológicos que constituem as funções de forças que atuam sobre os sistemas, levando em consideração de que a atmosfera e o lagos estão inteiramente inter-relacionados (ANDRADE, 2013).

No que tange os estudos sobre a erosão, é crucial destacar as diversas linhas de debates sobre vulnerabilidade, que diz respeito ao reconhecimento de diversos graus de sensibilidade/susceptibilidade do ambiente aos processos erosivos, o que pode ser depreendido no trecho a seguir:

A deposição e fluxo desses sedimentos podem vir a impedir a operação do aproveitamento quando o sedimento depositado alcança a cota da tomada d'água. Essa retenção de sedimentos no reservatório é de certa forma benéfica, pois promove a limpeza da água para seus diversos usos, embora a 
sedimentação contínua possa resultar em assoreamento indesejável (Carvalho 1994 apud Loureiro 2008).

A erosão pode ser definida como um grupo de processos sob os quais material terroso ou rochoso é desagregado, decomposto, deslocado e depositado pela ação combinada com outros processos naturais e exposição das rochas a condições diferentes de sua formação (GUY, 1970). Em outras palavras, e tratando especificamente do risco de desastres, destaca-se:

\begin{abstract}
A erosão, o transporte e a deposição de sedimentos são questões ambientais que afetam a sociedade através do decréscimo da produtividade agrícola, da diminuição da capacidade dos reservatórios, da intensificação das inundações e da redução da disponibilidade hídrica, entre outros (FARIAS, 2008 apud FROTA, 2012. p. 56).
\end{abstract}

Os processos erosivos, responsáveis pela produção de sedimentos, são decorrentes da presença de condições favoráveis a seu desenvolvimento, podendo ser acelerados pelas atividades antrópicas, especialmente, pela remoção da cobertura vegetal, construções de estradas e impermeabilização do solo decorrente de sua compactação, devido ao manejo inadequado do solo (ALMEIDA FILHO, 2008).

Santos e Silva (2020), estudando as condições hidrossedimentológicas no Lago do Amapá, um paleomeandro do rio Acre, em Rio Branco, identificaram a influência do uso e ocupação da terra para o aporte de sedimentos no talvegue daquele ambiente, assim como, observou-se a intensa quantidade de sedimentos em suspensão na margem correspondente à presença de estrada ou vacinais próxima, atribuindo-se uma intensa lavagem ou wash load de material fino transportado por runoff até o leito do Lago.

É de conhecimento geral que nem todo o sedimento que passa por uma secção transversal de um curso d'água é governado pelas mesmas leis. As características do movimento das partículas podem ser influenciadas pelo seu tamanho, forma e peso, além do regime de escoamento, da velocidade da corrente, dos obstáculos no leito, da declividade, forma do canal, entre outros (BELLINASO; PAIVA, 2007).

Além disso, Brune e Allen (1941) descreve os principais fatores que influenciam na deposição dos sedimentos em reservatórios, sendo eles: a quantidade de sedimento que entra no reservatório; a capacidade de retenção do reservatório; a quantidade de sedimentos acumulados e o modo de operação do reservatório.

Com a intenção de entender parte da dinâmica de transporte e deposição de sedimentos em corpos lênticos, este artigo propõe uma metodologia aplicada à coleta e monitoramento da decantação de sedimentos em 2(dois) açudes no campus da Universidade Federal do Acre 
(UFAC). Tendo em vista a indisponibilidade de um aparador, este trabalho propõe a elaboração do dispositivo (aparato) de coleta de sedimentos decantados, este é descrito todo seu processo de construção e manuseio no capitulo 2.2 , denominando-se de coletor de sedimentos de fundo para corpos lênticos.

O texto está estruturado em quatro seções, incluindo está introdução. No capítulo 2 é feita uma descrição mais detalhada da metodologia aplicada nesta pesquisa para o cálculo de concentração de sedimentos, com a descrição de todas as variáveis envolvidas: criação do aparato, coleta e as análises laboratoriais. No capítulo 3 são apresentados os resultados obtidos desta pesquisa. E o capítulo 4 apresenta, por fim, as conclusões e recomendações deste artigo. Espera-se que as reflexões geradas neste trabalho contribuam para adoção de práticas voltadas para conservação de lagos, e consequentemente para a atenuação dos impactos promovidos pelo manejo inadequado das áreas do estudo.

\section{METODOLOGIA}

\subsection{Descrição da área de estudo}

A área de estudo está localizada na Cidade de Rio Branco - Acre, nas coordenadas $9^{\circ} 57^{\prime} 14.00^{\prime} \mathrm{S}$ e $67^{\circ} 52^{\prime} 1,45^{\prime} \mathrm{W}$. Os pontos escolhidos para amostragem encontram-se dentro da área do Campus da Universidade Federal do Acre. O que facilitou a coleta das amostras do presente trabalho. A figura 1 apresenta a localização dos açudes.

Figura 11: Mapa de Localização da Área de Estudo

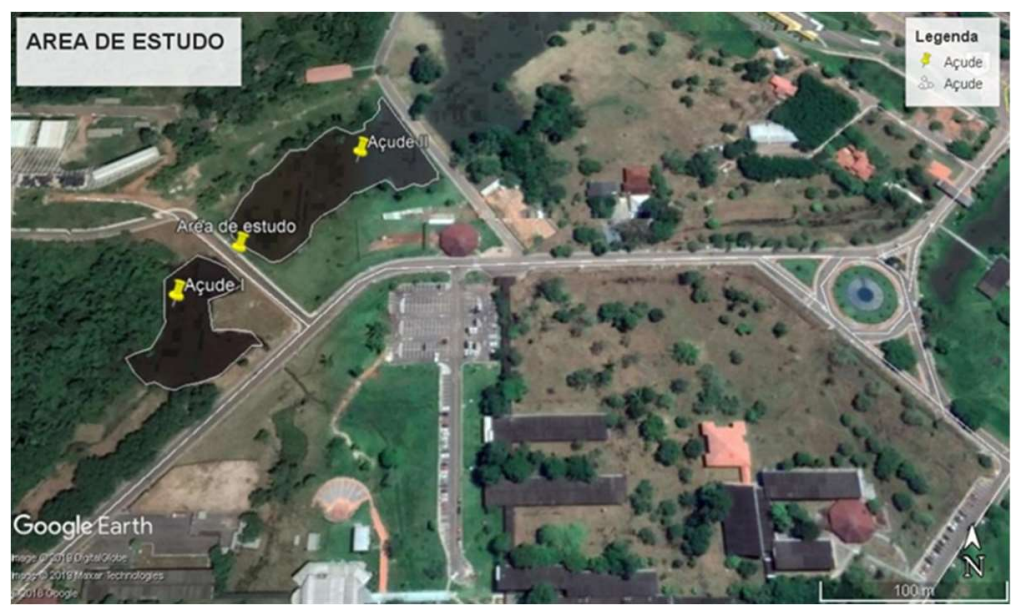

Fonte: próprio autor, produzido na plataforma Google Earth. 
Desta forma, a área de estudo, acolhe uma série de relações entre diversos agentes sociais que presenciam e participam mais intensamente das transformações que ali ocorrem. Cabe ressaltar que o açude I apresenta uma área de 3.450,14 $\mathrm{m}^{2}$, com aproximadamente $40 \%$ de sua mata ciliar preservadas, incluído a rede de drenagem que alimenta o referido lago, já o açude II, apresenta uma área de $6.809,53 \mathrm{~m}^{2}$ e suas águas são vertidas pelo açude I, e não apresenta mata ciliar.

\subsection{Procedimento para a construção do aparato}

O aparato foi inicialmente projetado com base nas técnicas de coleta descritas no Guia Nacional de Coleta, no qual apresenta diversos procedimentos de coleta de sedimentos precipitados em áreas de lagos (CETESB,1999).

Figura 12: Projeto do aparato

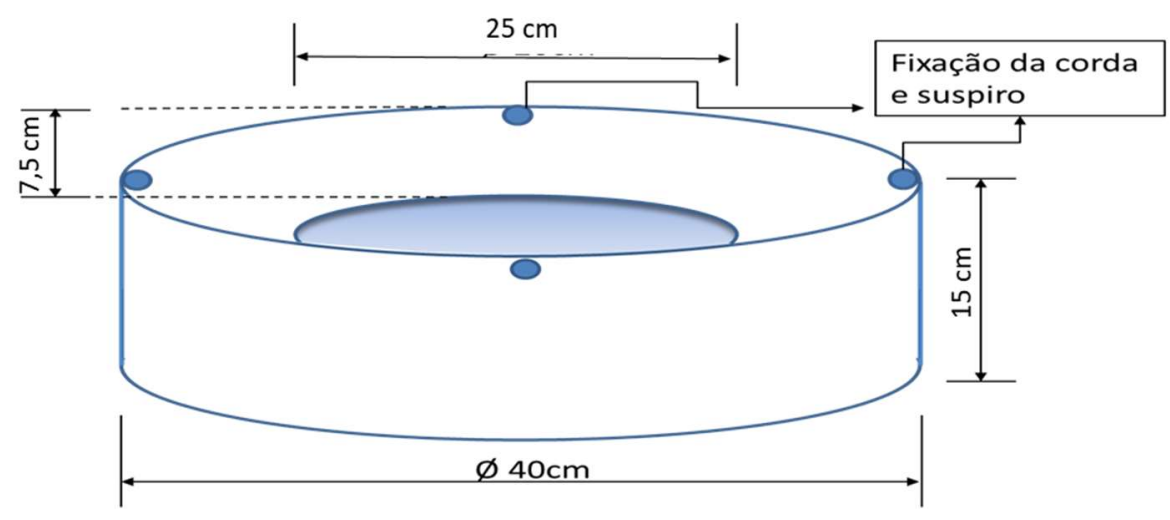

Fonte: próprio autor

O aparato é uma armadilha temporal, construído de materiais recicláveis, para sua construção utilizou-se balde de $18 \mathrm{~L}$ de gordura vegetal com $28 \mathrm{~cm}$ de diâmetro (FIGURA 3.A), foi feita uma adaptação do projeto inicial para a medida do balde. Considerando que o balde apresentava uma altura muito elevada, o que dificultaria o fluxo da água pelo o equipamento, cortou-se o balde a $13 \mathrm{~cm}$ do fundo e aproveitou-se a parte superior do balde para reforçar a estrutura lateral (FIGURA 3.B), servindo como uma segunda camada, para a segurança da coleta e um melhor aproveitamento do material.

Ao fundo do aparato, foi fixado um bloco de tijolo maciço para facilitar a submersão do aparato no lago para auxiliar a identificação do aparato foi inserida uma garrafa pet acoplada 
ao balde por uma corda, para facilitar sua identificação no momento das coletas (FIGURA 3.C) conforme apresentado a seguir.

Figura 13: Desenvolvimento do aparato
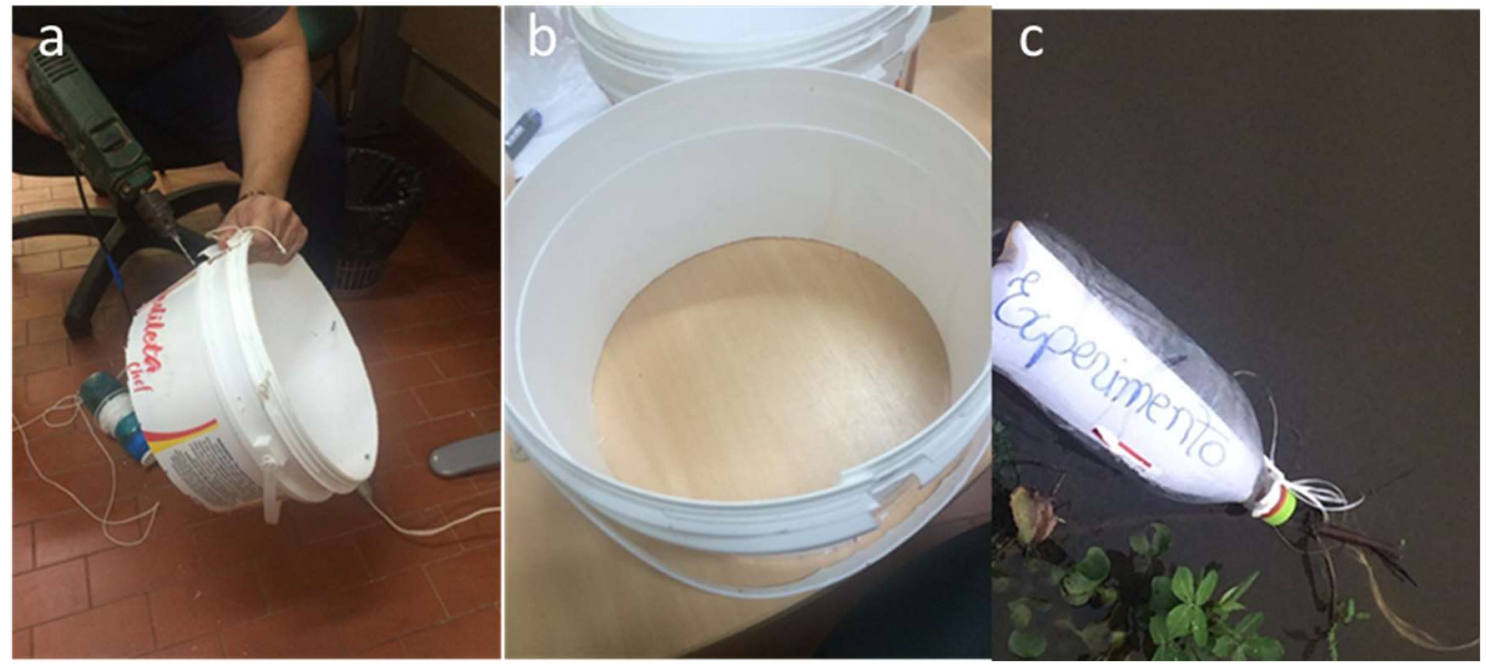

Fonte: próprio autor

\subsection{Coletas das amostras (água + sedimentos)}

O método de amostragem de sólidos depositados utilizados neste estudo é o método pontual, pois o tipo de análise deste estudo deve-se calcular o tempo de amostragem. Sendo assim, as coletas dos sedimentos do Açude I e II foram feitas no período de 13/05 a 23/05 de 2019 (|Tabela 1).

Tabela 1: Desenho Amostral

\begin{tabular}{ccc}
\hline Açudes & Amostras & Intervalo \\
\hline \multirow{2}{*}{1} & 1 & $13 / 05-15 / 05(48 \mathrm{~h})$ \\
& 3 & $15 / 05-20 / 05(120 \mathrm{~h})$ \\
& 5 & $13 / 05-23 / 05(192 \mathrm{~h})$ \\
\hline \multirow{2}{*}{2} & 2 & $13 / 05-15 / 05(48 \mathrm{~h})$ \\
& 4 & $15 / 05-20 / 05(120 \mathrm{~h})$ \\
& 6 & $13 / 05-23 / 05(192 \mathrm{~h})$
\end{tabular}

Fonte: Próprio autor.

Para a definição dos pontos de coleta, foi realizado um reconhecimento prévio da área, onde foi possível determinar que as coletas fossem feitas em dois pontos de cada açude. No 
açude I foram instalados os aparatos 1, 3 e 5 e no açude II, os aparatos 2, 4 e 6. É importante salientar, que infelizmente os aparatos 4 e 6 instalados no açude II, foram alterados de lugar, sendo que o aparato 6 , foi extraviado do local de pesquisa. O aparato 4 por ter sido alterado do lugar (por terceiros), perdeu-se o material decantado.

Além deste critério foi observado também disposição dos aparatos, que além de evitar a coleta de amostras em pontos muito próximos, apresenta as mesmas vantagens da subdivisão da área com a possibilidade de redução de pontos de amostragem, permitindo uma boa representatividade da área (CETESB, 1999).

A ideia inicial era determinar se tinha variação de sedimentação por decantação em função do número de horas que cada aparato passou submerso. Sendo instalados dois aparatos no dia 13/05/2019 em cada açude, sendo que as amostras 1 e 2 foram retirados no dia 15/05 (48h), e novamente reinstalados (amostras 3 e 4), para coletarem sedimentos até o dia 23/05, quando as amostras 5 e 6 foram retirados.

Em cada amostra realizada, foram retiradas amostras de água + sedimentos em suspensão e decantado no aparato. Para diminuir a influência do material que ainda estava em suspenção dentro do aparato (ou seja, material que ainda não tinha decantado), extraiu-se uma amostra de $500 \mathrm{ml}$ da água de dentro do aparato, para quantificar o percentual de material em suspensão, e, posteriormente ser descontado do material que ainda estava em suspensão dentro do aparato.

Para o procedimento em campo, a otimização da amostragem foi de fundamental importância. Neste contexto, o aparato foi submerso na profundidade de aproximadamente 1 metro, após o tempo pré-determinado foram retirados com o cuidado para não desagregar o material decantado no fundo. Em seguida, todo material retido no aparato foram transferidos para um recipiente opaco e identificado com as seguintes informações: a data, a hora, o numero do açude correspondente a cada amostra, e por fim foram acondicionados em sacos plásticos escuros, para evitar a proliferação de algas (CETESB, 2011).

\subsection{Procedimentos laboratoriais}

As leituras das amostras foram realizadas no laboratório de Geomorfologia e Sedimentologia, vinculado ao curso de Geografia na Universidade Federal do Acre (UFAC). Primeiramente, as amostras foram divididas em proveta graduada de $1000 \mathrm{ml}$, para determinação do volume total retido em cada coleta, sendo que na última proveta, tomou-se o 
cuidado de agitar o recipiente de coleta para garantir a retirada de todo o material decantado no fundo.

De cada proveta foi retirada uma amostra de $50 \mathrm{ml}$, para determinação da concentração de sedimentos, conforme a metodologia descrita abaixo:

i. Separação e limpeza dos béqueres com capacidade de $50 \mathrm{ml}$;

ii. Secagem dos béqueres em estufa a $105^{\circ} \mathrm{C}$ durante o mínimo de $60 \mathrm{~min}$;

iii. Pesagem dos béqueres em balança analítica Fa2204c;

iv. Separação dos $50 \mathrm{ml}$ de cada proveta;

v. Pesagem dos béqueres com os $50 \mathrm{ml}$ das amostras;

vi. Secagem dos beques com as amostras de $50 \mathrm{ml}$ em estufa a $105^{\circ} \mathrm{C}$, por 24 horas;

vii. Nova pesagem dos béqueres, após a evaporação de toda água da amostra (FIGURA 4).

Figura 14: Amostra após 24h na estufa

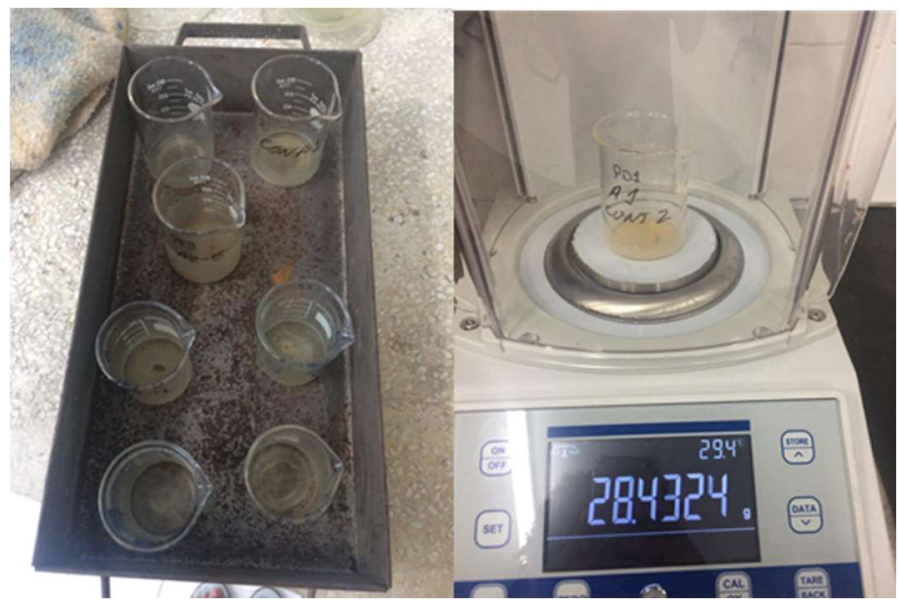

Fonte: próprio autor

\subsection{Quantificação do material decantado}

Para fins desta pesquisa, foram elaboradas tais equações apoiando-se na rotina apresentada acima. Isto posto, optou-se por trabalhar com o método de amostragem intencional no processo de quantificação do material decantado, aplicando a rotina de cálculos a seguir:

a) Concentração dos sedimentos " $C_{s}$ " 
$C_{S}=\left(\frac{B_{V}-B_{S S}}{Q_{A}}\right) * 1000$

Onde:

$B V-$ Béquer vazio $[\mathrm{g}]$;

$B S S$ - Béquer com os sedimentos secos [g];

$Q A$ - Volume da amostra [ml].

b) Quantificação dos sedimentos totais decantado no aparato " $S_{T A}$ ":

$S_{T A}=\sum_{C_{S i}}^{C_{S 1}}-C_{S(\text { cont. })} \quad[\mathrm{g}]$

Onde:

$C_{S 1}$ - Concentração de sedimento da primeira proveta $[\mathrm{g} / \mathrm{L}]$;

$C_{S i}$ - Concentração de sedimento da última proveta $[\mathrm{g} / \mathrm{L}]$;

$C_{S(\text { cont.) }}$ - Concentração de sedimento da amostra de controle $[\mathrm{g} / \mathrm{L}]$.

c) Quantificação dos sedimentos decantados por hora no aparato " $V_{\text {Sed }}$ "

$V_{\text {Sed }}=\frac{S_{T A}}{T} \quad[\mathrm{~g} / \mathrm{h}]$

Onde o " $T$ ” é o tempo que o aparato ficou submerso [h].

d) Estimativa da quantidade de sedimentos decantados por hora em um $\mathrm{m}^{2}$ " $V$ 'Sed":

$V_{\text {Sed }}^{\prime}=\frac{V_{\text {Sed }}}{A_{\text {apa }}} * \quad\left[\mathrm{~g} / \mathrm{m}^{2} \mathrm{~h}\right]$

Onde o "Aapa" é a área do fundo do aparato $\left[\mathrm{m}^{2}\right]$.

\section{RESULTADOS E DISCUSSÃO}

Aqui são apresentadas as informações obtidas a partir da aplicação da metodologia descritas anteriormente e as discussões pertinentes aos resultados.

Para embasar os resultados é conveniente relatar que Rossato e Silva (2004) alertam que o aumento na produção de sedimentos em bacias hidrográficas está relacionado aos processos de urbanização em regiões próximas, pois ela promove a alteração da cobertura do solo através 
da colocação de pavimentos impermeáveis e implantação de dutos subterrâneos de escoamento pluvial. Essas mudanças acarretam uma redução da infiltração do solo, aumentando o escoamento superficial diretamente para rede de drenagem.

O ciclo hidrossedimentológico ocorre paralelamente ao ciclo hidrológico nas bacias hidrográficas, pois é dependente do ciclo hidrológico. É um ciclo aberto que envolve o deslocamento, o transporte e o deposito de partículas sólidas presentes na superfície da bacia. Nesse âmbito, durante o período desse estudo foi observada a variação da precipitação no período anterior a data de retirada dos aparatos, podendo ser caracterizadas por fenômenos de pequena intensidade, que somaram apenas $31,1 \mathrm{~mm}$ ocorridos nos 15 dias anteriores.

Todo curso d'água normalmente apresenta um equilíbrio em relação ao transporte de sedimento, seja por arrasto e saltitação junto ao leito, seja em suspensão na corrente, e existe uma tendência natural para que este seja depositado quando o fluxo natural de sedimentos ao encontrar água com menor velocidade (alteração do fluxo) começa a se depositar, conforme a maior ou menor granulação das partículas e a menor ou maior turbulência do escoamento (GLYMPH, 1973 apud CARVALHO, 2000).

Dessa forma, foi possível observar a evolução da sedimentação em função do tempo, apenas no açude I, onde, em decorrência da proliferação de material orgânicos, observados no período, acarretou o aumento do material (sedimento e matéria orgânica em decomposição), decantado no aparato em função do tempo (Figura 5).

Para Glymph (1973) a quantidade de sedimento depositada em um dado reservatório depende da quantidade de material em suspensão enviada para o mesmo e da capacidade do reservatório reter as partículas em suspensão. Nesta acepção, foi possível observar na figura 5, que a quantidade de sedimentos nas primeiras 48 horas nos açudes I e II, apresentou valores próximos. 
Figura 15 - Evolução da sedimentação por decantação em função do tempo.

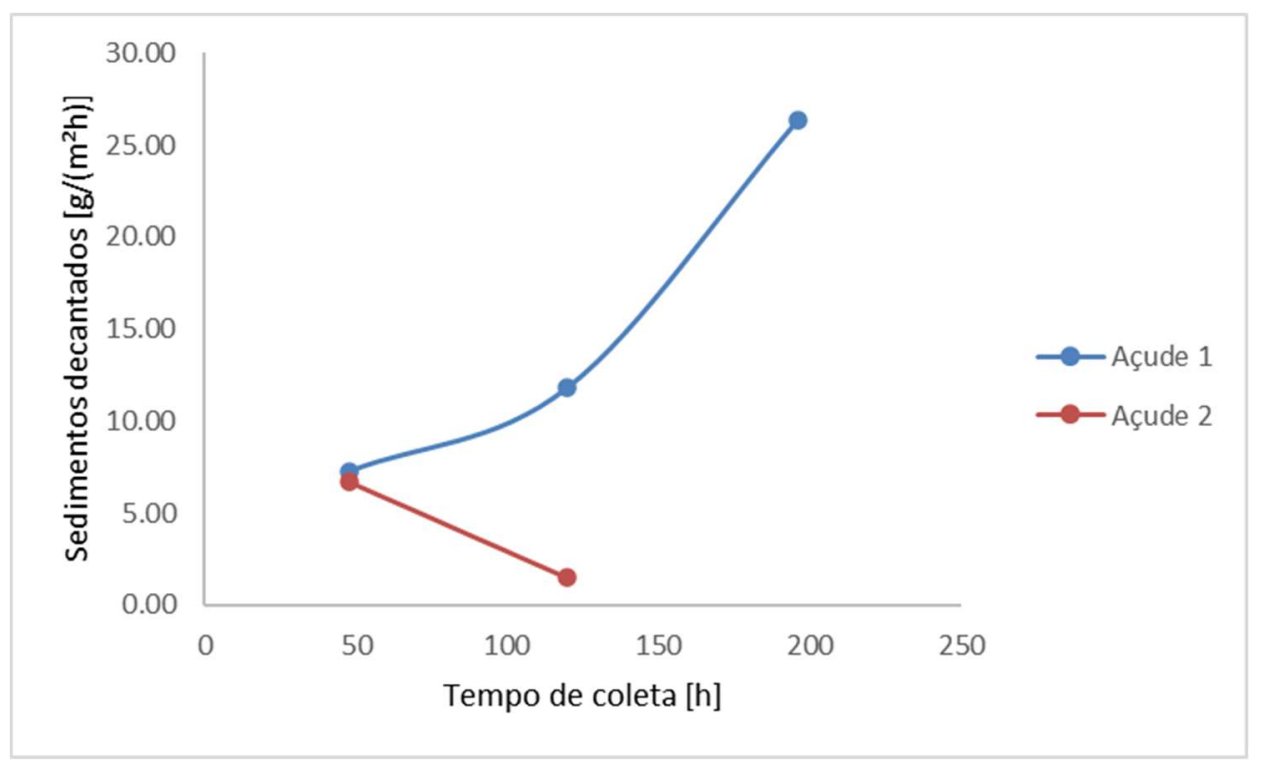

Fonte: Araújo, 2019

No Entanto, em 120h notamos uma grande disparidade de valor do material decantado nos açudes, sendo que o açude I obteve $8,8 \%$ a mais de material decantado, provavelmente porque parte do material aportado, decantou-se no açude I, antes de chegar ao açude II.

Vale lembrar, que alguns sedimentos são depositados apenas temporariamente, pois eventos subsequentes podem ocorrer uma suspenção e movê-los através do sistema de transporte (FOSTER, 1982; GOLDENFUN, 1991). Dessa forma, o aumento do tempo de espera com aparatos para coleta do material decantado, provavelmente não apresentará um comportamento linear em função do tempo, pois a concentração dos constituintes de um corpo d'água pode variar ao longo do tempo, num mesmo ponto, de forma aleatória ou cíclica em função das características das contribuições recebidas ou das variáveis meteorológicas (CETESB, 2011).

É necessário enfatizar que os resultados obtidos nesse estudo aqui apresentados, embora tenha sua importância, devem ser considerados como um retrato momentâneo do transporte e consequentemente a decantação nos açudes, não podem ser considerados como valores representativos para as estações seca e chuvosa, tão pouco permitir inferir estimativa a respeito do total anual de sedimentos em suspensão transportados, visto o reduzido número de amostragem realizada. 
Gätcher e Meyer (1993) destacam que as bactérias contribuem para a mineralização de material orgânico dissolvido e particulado nos sedimentos em lagos, desta forma, a presença de mateira orgânica nas amostras coletadas pode ter sido originária do escoamento de material a partir das margens. Além disso, vislumbra-se que a produção de matéria orgânica possibilita o aumento de sedimentos decantados.

Por fim, é importante mencionar, que os processos de decantação podem ser influenciados pela presença de poluentes, que não foi avaliado nesse estudo, onde os metais e outros compostos potencialmente poluentes, ligados ao sedimento, podem ser remobilizados e liberados para água causando efeitos adversos nos organismos terrestres e aquáticos (ZERFASS; ZERFASS, 2016).

\section{CONCLUSÃ̃o}

Considerando os dados iniciais, oriundo da primeira etapa do projeto, este trabalho chegou as seguintes conclusões:

- A amostragem de sedimentos à primeira vista parece simples, mas quando são considerados os diversos fatores que podem influenciá-la, como profundidade e velocidade de correntes são fundamentais a adoção de rotinas e protocolos de coletas padronizados para redução das incertezas.

- Preliminarmente, o aparato apresentou bons resultados, mas recomendam-se novas repetições ao longo do ano hidrológico, para medir os efeitos da precipitação no carreamento dos sedimentos e a influência da proliferação de matéria orgânica no material decantado, que é mais evidente em períodos não chuvosos.

- Uma das benesses desse equipamento refere-se à possibilidade de se obter uma medição da taxa de decantação em um curto período; Outra eventualidade é a instalação simultânea em vários locais; a simplicidade e baixo custo de de sua construção; Além disso, o aparador mostrou potencial em gerar informações que contribuem para as políticas públicas de outorga para licenciamento de construção de barragens e principalmente estimar a vida útil da barragem decorrente do seu assoreamento que ocorrem ao longo do tempo.

- Dentre as desvantagens cita-se a necessidade de análise posterior das amostras em laboratório; Demanda de um número maior de pessoas envolvidas na instalação; além disso, é necessário ressaltar que podem ocorrer: possíveis amostragens adicionais durante a elevação e/ou abaixamento do instrumento e perdas durante a remoção dos 
sedimentos no interior do aparato e os extravios por terceiros como ocorrido durante esta pesquisa.

\section{REFERÊNCIAS}

ALMEIDA FILHO, G. S. de. Processos erosivos urbanos. In: Ambiente e Sedimentos. POLETO, C. (Org.). Porto Alegre: ABRH, 404 p., 2008.

ANDRADE, A. B. P. Modelo inteligente de avaliação de qualidade de água e da qualidade ambiental para um reservatório tropical oligo-mesotrófico. Orientador: Marley Bernadezz Rebuzzi Vellasco; Portificia Univerdidade Cátolica do Rio de Janeiro, 229 p., 2013. Disponível $\mathrm{em}$ : https://www.maxwell.vrac.puc-rio.br/35322/35322 1.PDF. Acesso em: 28.05.19

BELLINASO, T. B.; PAIVA, J. B. D. 2007. Avaliação da produção de sedimentos em eventos chuvosos em uma pequena bacia hidrográfica semi-urbana de encosta. Revista Brasileira de Recursos Hídricos, v.12, n. 13, p. 170-181. Disponível em: < $\underline{\text { https://abrh.s3.sa-east- }}$ 1.amazonaws.com/Sumarios/17/2287db2c92588abbbd41c518025e3fec 29f18ccb876737648c 767e44d37f6a7b.pdf $>$ Acesso em: 11/05/2020.

BRUNE,G.M; ALLEN,R.E. A consideration of factor influencing reservoir sedimentation. IN: The Ohio Valley Region. American Geophysical Union. V2. 1941.

CARVALHO, N.O. assoreamento de reservatórios - conseqüências e mitigação dos efeitos. In: IV Encontro Nacional de engenharia de Sedimentos. Santa Maria-RS. Cdrom. 1-22p. 2000.

CETESB. Amostragem do solo 6300. Projeto CETESB-GTZ, 1999. Disponível: http://www.cetesb.sp.gov.br/solo/areas contaminadas/anexos/download/6300. Acesso em: 01.06.19.

CETESB. Guia nacional e preservação de amostras: água, sedimentos, comunidades aquáticas e fluentes líquidas / Companhia Ambiental do Estado de São Paulo; Organizadores; Carlos Jesus Brandão...[et. al.] São Paulo: Brasília: ANA, 327p., 2011.

FOSTER, G. R. Modeling the erosion process. In: HAAN, C. T.; JOHNSON, H. P.; BRAKENSIEK, D. L. Hydrologic Modeling of small watersheds. St. JOSEPH, ASAE. Chap. 1982. p. 297-380. Disponível: $<$ http://www.sciencedirect.com/science/article/pii/0308$\underline{521 X(84) 90033-7}>$ Acesso em: 11. 05. 2020.

FROTA, P. V. Potencial de Erosão na Bacia Hidrográfica do Açude Orós - CE. (Tese de Doutorado em Engenharia Florestal), Publicação PPGEFL. TD - 20/2012 Programa de PósGraduação em Engenharia Florestal, Universidade de Brasília, 2012. Disponível em: <file://C:/Users/Alessandro/Downloads/2012_PatriciaVasconcelosFrota.pdf $>$. Acesso em: 11.12 .19

GÄTCHER, R.; MEYER, J.S. The Role of Microorganisms in Mobilization of Phosphorus in Sediments. Hydrobiologia, v. 253, p. 103-121, 1993. 
GLYMPH.L.M. Sedimentation of Reservoirs. IN; ACKERMANN.W.C et al, ed. Man -made lakes: their problems and envirommental. Washington DC. American Geophysical Union 342348p. 1973.

GUY, H. P. Fluvial sedimentos Concepts. In: Aplications of hydraulics. USGS. Techniques of Water Resources Investigations of the United States Geological Survey. TWRI 3 - C1. Arlington. VA. 55 p.

LOUREIRO, D. D. T. Métodos atuais e novas tecnologias para o monitoramento do transporte de sedimentos em rios: necessidade de dados e incertezas envolvidas. Dissertação (Mestrado) - Escola de engenharia de São Carlos, universidade de São Paulo, 2008. 91p.

PAIVA, J. B. D.; PAIVA, E. M C. D. 2003. Hidrologia Aplicada à Gestão de Pequenas Bacias Hidrográficas. FINEP, ABRH, Porto Alegre.

ROSSATO, M. S.; SILVA, D. L. M. A reconstrução da paisagem metropolitana de Porto Alegre: o tempo do homem e a degradação ambiental da cidade. In: VERDUM, R, BASSO, L.A., SUERTEGARAY, D.M.A. (Orgs.). Rio Grande do Sul: paisagens e territórios em transformação. Porto Alegre: Ed. da UFRGS, 2004.

SANTOS, W. L.; SILVA, P. M.. Análise da concentração de sedimentos em suspensão (CSS) em ambiente fluvial lêntico no sudoeste amazônico - Acre - Brasil. Anais do XI Simpósio Nacional de Geomorfologia. SINAGEO: Maringá/PR, 2016. Disponível em: $<$ http://www.sinageo.org.br/2016/trabalhos/3/3-463-126.html $>$ Acesso em: 12 mai/2020.

SILVA, A. M.; SCHULZ, H. E. in: Camargo, P. B. Erosão e Hidrossedimentologia em Bacias Hidrográficas. Ed. RIMA. 138 p., 2004.

ZERFASS, H; ZERFASS, G. S. A. A sedimentação em uma abordagem sistêmica. Artigo Terra Didática, n.12, p.140-171, 2016. DOI: https://doi.orgb/10.20396/td.v12i2.8646322. 